\title{
Soporte vital básico: Efectividad de una intervención en adolescentes empleando el QR Basic Life Support: Effectiveness of an intervention in adolescents using the QR
}

\author{
$\mathbf{M}^{\mathrm{a}}$ Angeles Manzano-Felipe ${ }^{1^{*}}$, Carmen Pérez-García ${ }^{2}, \mathbf{M}^{\mathrm{a}}$ Irene Fernández-Morales ${ }^{2}$ \\ 1 Distrito Sanitario Bahía de Cádiz-La Janda \\ ${ }^{2}$ Hospital de Valme. Sevilla
}

Fecha de recepción: 04/06/2015 - Fecha de aceptación: 02/02/2016

\section{Resumen}

Objetivo: Determinar la efectividad de una intervención educativa en Soporte Vital Básico (SVB) empleando el quick response code (QR) en términos de mejora de conocimientos teóricos y habilidades prácticas en alumnos de $4^{\circ}$ ESO de San Fernando (Cádiz),España. Metodología: Compuesta de dos etapas:1ªnvestigación bibliográfica desde 2008 a 2014 en las bases de datos PubMed, CuidenPlus, Dialnet, SciELO, Embase, el Índice Médico Español (IME) y $2^{\mathrm{a}}$ Investigación cuasi-experimental pre y post intervención con la participación de 246 adolescentes a quienes se les realizó una intervención y posteriormente se les aplicó un cuestionario auto administrado de conocimiento teórico, un check-list de habilidades prácticas y un cuestionario de satisfacción. Se empleó la prueba ANOVA y prueba de rango post hoc HSD de Tukey. Resultados: La variable conocimiento teórico muestra diferencias significativas $(\mathrm{p}=0 \%)$ para todos los momentos a excepción de los momentos post-intervención inmediata y la post-intervención de los 6 meses, en cambio la variable adquisición habilidades prácticas muestra diferencias significativas $(p=0 \%)$ para todos los momentos de la intervención. El grado de satisfacción global es del 99\%. Conclusión: Existe evidencia estadísticamente significativa $(p<0.0000)$ de la efectividad de la intervención en SVB con empleo del QR y un elevado grado de satisfacción por parte de los alumnos.

Palabras clave: Resucitación Cardio Pulmonar básica, Educación Secundaria, Enfermería, Tecnología de la Información, Proyectos de Tecnologías de Información y Comunicación

\section{Abstract}

Objective: To assess the usefulness of an educational intervention to teach the theory and practical skills about basic life support to high school students from San Fernando(Cádiz). Methods: It is a study which consists of two reports: $1^{\text {a }}$ A literature review of the year 2008-2013 in English and Spanish in the database PubMed, CuidenPlus, Dialnet, SciELO, Embase and Índice Médico Español (IME). $2^{\text {a }}$ Semi-experimental research carried out in a sample of 246 secondary school students in San Fernando, Cádiz. An educational intervention was developed according to the ILCOR 2015 guidelines. The students, who were an experimental group and a control group at the same time, took a test before and after instruction in order to detect change in knowledge and skills. ANOVA's test was used to assess the differences in the score changes of the dimensions of the scale employed. Results: Viable data were obtained for 246 students. After analysis of variance, the variable theoretical knowledge shows significant differences $(p=0 \%)$ for all the moments with the exception of the moments immediate post-intervention and the post-intervention of 6 months and the variable practical skills shows significant differences $(p=0 \%)$ for all the moments of the intervention. The grade of global satisfaction was $99 \%$. Conclusions: The educational intervention in basic life support with QR achieved a significant increase in theoretical knowledge and practical skills. The relevance of these results rests on the lower cost per instructional session for the $Q R$, which can be used an unlimited number of times without supervision. Furthermore, the QR can be distributed free of charge to institutions or individuals.

Keywords: Cardiopulmonary Resuscitation, Education Secondary, Nursing, Information Techonlogy, Information Technologies
and Communication Projects

*Correspondencia: maanmafe@gmail.com 


\section{Introducción}

En Europa ocurren aproximadamente unas 375.000 paradas cardiorrespiratoria (PCR) al año.Un porcentaje muy importante de las mismas suceden fuera del hospital. "En España se produce un paro cardíaco cada 20 minutos, ocasionando cuatro veces más muertes que los accidentes de tráfico" (Perales, y otros 2003) y unas 25.000 personas fallecen por infarto agudo de miocardio antes de poder recibir asistencia médica (Ministerio de Sanidad y Política Social, 2007). A pesar de la mejoría de los servicios de emergencias éstos nunca podrán llegar a la totalidad de los casos con la suficiente rapidez, de ahí que sea preciso elaborar o mejorar estrategias orientadas a disminuir los tiempos, hasta la desfibrilación precoz y a enseñar las maniobras básicas de reanimación cardiopulmonar (RCP) a la población (Peña, 2013).

Actualmente el $60 \%$ de los paros cardíacos se producen en presencia de testigos y menos del $30 \%$ de las PCR extra hospitalarias son reanimadas inicialmente por las población general. La instauración de maniobras de RCP por las personas que han presenciado el paro aumenta en siete veces las posibilidades de supervivencia (Álvarez, Alvarez, \& Rodríguez, 2001; Sasson, Rogers, Dahl, \& Kellermann, 2009; Berg, y otros, 2010; Travers, y otros, 2010).

Diversos estudios han demostrado que el tiempo transcurrido entre la parada cardiaca y el inicio de la reanimación cardiopulmonar es uno de los factores pronósticos más importantes. Se sabe que la demora en la asistencia en un minuto, decrementa en un 10\% la posibilidad de supervivencia y tras 10 minutos sin atención, las posibilidades de supervivencia son mínimas (Coma, Garcia , Ruano, Loma, Malpartida, \& Rodriguez, 2009). La RCP básica precoz mejora el pronóstico de la PCR tanto en niños como en adultos. Es necesario que las personas que atienden inicialmente al individuo que ha sufrido una PCR realicen RCP básica hasta que lleguen los servicios de emergencias. El cómo hagamos llegar esta formación a los diferentes activos es muy diversa.

Una de las posibles formas de transmitirla es a través del empleo de las Tecnologías de la Información y de la Comunicación (TIC's) las cuales ofrecen infinidad de oportunidades y cuando se utilizan de forma justificada y dinamizada en un contexto curricular adecuado tienen como objeto el enriquecer, estimular y favorecer un aprendizaje significativo por parte de los estudiantes.

"Un estudio realizado por el Instituto Nacional de Educación Multimedia de Japón (ELMO,2013, citado por Casanova \& Molina, 2013) demostró que un aumento en la exposición de estudiantes a las TIC's mediante la integración curricular de educación tiene un impacto significativo y positivo en el rendimiento estudiantil, especialmente en términos de "conocimiento-comprensión", "habilidad práctica" y "presentación de habilidad" en materias tales como matemáticas, ciencias y estudios sociales" (Casanova \& Molina, 2013, p. 934). En Europa también hemos dado pasos en esta dirección, así "el marco del Espacio Europeo de Educación Superior (EES) y, en general, la actual sociedad de la información, exigen que desde el punto de vista de la enseñanza se reduzcan las 
prácticas memorístico-reproductoras a favor de prácticas socio-constructivistas centradas en los alumnos y en el aprendizaje autónomo y colaborativo (Declaración de Praga, 2001).

La forma de educar empleando diferentes modelos didácticos, no debe dejar hoy en día a un lado el empleo de las TIC's, de hecho las experiencias en el ámbito de la educación primaria y secundaria de estas herramientas se está extendiendo en los últimos años (Hernandez, 2011). Por ende, el empleo de las nuevas tecnologías contribuye a una mayor difusión de información, además de colaborar en la interacción de personas e instituciones (Carrillo-Larco \& Curioso, 2013).

Son las TIC's herramientas computacionales e informáticas que procesan, almacenan, resumen, recuperan y presentan información representada de la más variada forma. Una de estas herramientas es el QR (del inglés Quick Response code) "códigos de respuesta rápida" (Wave, 2013), esta herramienta sirve para almacenar información que pueden leerse desde computadores personales, teléfonos móviles inteligentes o tabletas.

Aunque los códigos $Q R$ en su origen no fueron concebidos para un ámbito educacional, si nos brindan oportunidades (Bayonet, 2010) de ser utilizados como recurso educativo en el aula y fuera de ella ya que nos proporcionan información inmediata, nos sirven como recurso de aprendizaje y motivan a los alumnos a la vez que les permite ejercitar sus habilidades. (Casanova \& Molina, 2013) Decidimos realizar el proyecto de intervención en soporte vital básico (SVB) aplicando la herramienta QR en adolescentes de $4^{\circ}$ de enseñanza secundaria obligatoria (ESO) por varias razones:

1. La Fortaleza física que presentan los niños mayores de 13-14 años permite que realicen las compresiones torácicas con la misma calidad que los adultos.

2. Los adolescentes tienen una gran posibilidad de atender a víctimas en otros escenarios y cabe la posibilidad de que en la vida adulta, esos conocimientos sean también útiles.

3. La financiación de esta intervención no supone en España una barrera importante para implementar la enseñanza de la RCP en los colegios, puesto que El Plan Andaluz de Urgencias y Emergencias y el Plan de Atención a la Accidentabilidad 2007-2012 de la Consejería de Salud insta a los profesionales que realizan su labor asistencial en los dispositivos de cuidados críticos y urgencias (DCCU) a formar a la población en general en materia de SVB y primeros auxilios (Servicio Salud, 2015; Consejería de Salud, 2012)

4. Implementar en los currículos escolares la docencia de la reanimación y apoyarla con estrategias de recuerdo supondría la universalización de estas habilidades en un plazo de unos 50 años. Dado que la mayoría de las paradas cardiorrespiratorias recuperables se producen estando presente o cercano un reanimador potencial, los beneficios esperados en ese plazo serían razonables si se busca entrenar a los adolescentes para reanimar en cualquier escenario. 
5. El empleo de los móviles en población de esta edad está totalmente instaurado. Si aprovechamos las funciones que poseen, podemos potenciarlas a través del empleo del QR ya que estos códigos logran captar la atención al ser una herramienta novedosa debido a su original e innovador diseño, a la vez que nos permiten responder a las necesidades de esta población, tales como la búsqueda en la inmediatez (los alumnos solo deben capturar el código con su terminal e inmediatamente reciben el contenido) y la posibilidad de interacción (los alumnos buscan la diversidad e interactividad y los códigos QR se los proporciona, permitiéndole la interacción con Facebook, Twitter).

Sabiendo que la RCP básica sustituye de forma precaria las funciones vitales, pero permite ganar algunos minutos, para que así pueda aplicarse el tratamiento definitivo con mayores posibilidades de éxito, que multitud de estudios han demostrado cómo las tasas de supervivencia de las paradas cardíacas descienden si la RCP básica no es iniciada por los testigos antes de la llegada de los equipos profesionalizados, que la capacidad de aprendizaje en alumnos de secundaria y la posibilidad de realizar una RCP básica efectiva es posible, que el coste de la intervención en conocimiento de SVB en relación con los beneficios que aportaría en un futuro son ínfimos y que la utilización del QR como herramienta apenas supone coste, se decide realizar esta actividad, encuadrándola a su vez en el Programa de Información y Formación Juvenil para Educación Secundaria del programa Forma Joven de Andalucía (Junta de Andalucia. Consejería de Salud., 2012), por lo que obtenemos una transversalidad de la intervención a implicarse en ella tanto la Consejería de Salud como la Consejería de Educación. Por estas razones es por lo que nos planteamos este estudio.

El objetivo de este trabajo es llevar a cabo un estudio a fin de evaluar la efectividad de la intervención educativa de SVB, empleando QR, en términos de mejora de conocimientos teóricos y habilidades prácticas en alumnos de secundaria de la localidad de San Fernando (Cádiz), Andalucía, España.

\section{Material y método}

Este trabajo consta de dos partes perfectamente diferenciadas:

\section{$1^{\text {a }}$ Parte del estudio}

\section{Diseño}

Para la realización de esta parte se diseñó una búsqueda bibliográfica de publicaciones sobre el tema "el empleo de las TIC's para acercar los conocimientos en SVB a los alumnos de ESO, tanto en español como en inglés publicadas desde 2008 a 2014. Se empleó el Metabuscador GERIÓN (Biblioteca Virtual del Sistema Sanitario Público de Andalucía) y el Google Académico. Las bases de datos empleadas fueron: PubMed, CuidenPlus, Dialnet, SciELO, Embase, el Índice Médico Español (IME). Las palabras claves o descriptores DeCs según la base de datos utilizados en español fueron 
"Tecnología de la Información", "Resucitación Cardiopulmonar", "Educación" y "Servicios de Salud del Adolescente". En las bases de datos internacionales las palabras claves o descriptores DeCs empleadas fueron "Cardiopulmonary Resuscitation", "Education Secondary", "Nursing", "Information Technology", "Information Technologies and Communication Projects". Empleamos el operador booleano AND y desarrollamos diferentes estrategias de búsqueda según la base de datos. Fueron definidos como criterios de inclusión los artículos relacionados con educación en SVB en adolescentes, revisiones bibliográficas, programas de salud dirigidos a adolescentes y guías de actuación en SVB y como criterios de exclusión los estudios experimentales. La búsqueda fue realizada desde junio 2014 a marzo 2015.

\section{$2^{\mathrm{a}}$ Parte del estudio.}

\section{Diseño de estudio}

Para la realización de esta parte del estudio, se llevó a cabo un diseño de estudio cuasi-experimental pre y post intervención.

\section{Participantes}

La muestra fue seleccionada por muestreo aleatorio realizada entre los ocho institutos públicos de enseñanza secundaria (IES) de San Fernando, seleccionándose un total de cuatro institutos y estuvo formada por 246 alumnos de $4^{\circ}$ de ESO matriculados en el curso escolar 2015-2016 que cumplían los siguientes criterios de inclusión: estudiantes de $4^{\circ}$ de ESO matriculados en el curso escolar 20152016 que justificaron una asistencia del 99\% durante los meses en los que se repartieron las encuestas y aceptación voluntaria de participación en el estudio y como criterios de exclusión ser estudiantes matriculados en cursos de ESO diferentes de $4^{\circ}$ y no pertenezcan a San Fernando.

\section{Instrumentos}

Para la recogida de los datos se diseñaron tres cuestionarios, un cuestionario autoadministrado de conocimientos teóricos de elaboración propia que constaba de cinco preguntas para obtener datos sociodemográficos y ocho preguntas tipo test con cuatro posibles respuestas de conocimientos específicos en SVB de las cuales sólo era cierta una (anexo 1), un check-list de evaluación de habilidades de elaboración propia, adaptando el Test Raval Sud (Abril, y otros, 2010) para evaluación taller práctico (anexo2) y un tercer cuestionario para evaluación del grado de satisfacción que constaba de cuatro partes diferenciadas a evaluar (organización, actividad formativa, evaluación global y profesorado) con respuestas cerradas a evaluar entre 1 y 4 puntos, donde 1 es la puntuación más baja y 4 la puntuación más alta (anexo 3 ).

Para la exposición teórica se diseñó un cartel interactivo informativo, en el cual se hallaba nuestro QR que se diseñó con el generador de códigos QRHacker (www.qrhacker.com/) y al que se le asoció la url del video "Consejos sobre soporte vital básico" que pertenece al programa de la Consejería de 
Salud de la Junta de Andalucía "informarse.essalud" (Junta de Andalucía. Consejería de Igualdad, Salud y Políticas sociales, 2010) siendo éste de acceso y empleo libre (figura 1).

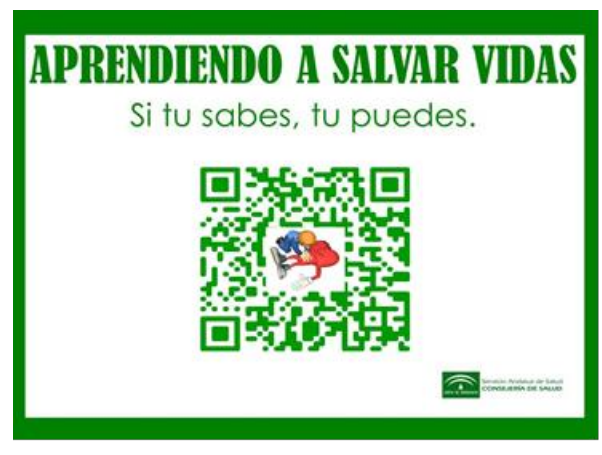

Figura 1: Aprendiendo a salvar vidas

\section{Procedimiento}

El procedimiento de la estrategia de intervención propuesta es de carácter educativo centrado en alumnos de secundaria. Esta intervención combina la adquisición de los conocimientos teóricos necesarios de SVB con la aplicación práctica de los mismos. Para aportar los conocimientos teóricos empleamos el cartel interactivo con el QR y para la adquisición de las habilidades se llevó a cabo un taller práctico.

El programa de la intervención estuvo a cargo de cuatro profesionales sanitarios de los cuales uno era Instructor de Soporte Vital Avanzado y los otros tres monitores de Soporte Vital Básico. Desde la entrada del alumno en el programa se estableció un procedimiento de información, consejo e intervención estandarizado.

Este procedimiento tenía varios componentes, en primer lugar se elaboró una carta de presentación dirigida al director del centro del IES solicitándole una cita para la presentación del proyecto y solicitarle la participación en el proyecto. Tras su aceptación se citaron a los alumnos a través del tutor, por clases independientes y días independientes (por ejemplo el lunes, miércoles y jueves) hasta completar el número de alumnos en $4^{\circ}$ de ESO existentes en el centro. En esta cita se les explicó el proyecto y se les pasó el cuestionario auto administrado de conocimientos teóricos (ver anexo 1). La duración prevista para la cumplimentación del cuestionario auto administrado fue de 20 minutos. Tras una semana del primer contacto se citaron nuevamente a los alumnos para realizar la intervención educativa grupal, basada en la explicación detallada del procedimiento de actuación en SVB desde punto de vista teórico empleando el cartel interactivo informativo con el QR y el taller práctico para las habilidades, para este último se dividió la clase en grupos de alumnos de no más de 8 alumnos por grupo. Tanto la exposición teórica como la práctica se realizó de manera estandarizada, siendo la duración de esta intervención fue de 90 minutos en total, la cual incluía la realizada por los monitores y la realizada por los alumnos. 
La recogida de datos se llevó a cabo en cinco momentos diferentes los cuales fueron: antes de la intervención (TEST-PRE_INTERV), tras la intervención inmediata (TEST-POST_INTERV_0), al mes de la intervención (TEST-POST-INTERV_1MES), a los 3 meses de la intervención (TEST-POSTINTERV_3MESES) y a los 6 meses de la intervención (TEST-POST-INTERV_6MESES).

Los cuestionarios auto administrados de conocimientos teóricos (ver anexo 1) fueron rellenados por todos los alumnos que participaron voluntariamente en la intervención, el check-list (ver anexo 2) de habilidades fue rellenado por cada monitor. El último día de contacto con los alumnos se realizó el cuestionario de satisfacción del alumno (ver anexo 3).

La información fue recogida por 4 monitores encargados de realizar los talleres a los alumnos a través de la observación y los cuestionarios y trasladada a los investigadores. Las intervenciones sobre los alumnos se llevaron a cabo en horario lectivo. Para su organización y puesta en práctica fue necesario establecer mecanismos de cooperación con los profesores.

\section{Análisis estadístico}

Para el análisis estadístico de los datos, se diseñó en primer lugar una plantilla para la trascripción de los datos recogidos con base de datos Microsoft Access en la que se reflejaban las diferentes variables a estudiar (edad, sexo, resultado académico de $3^{\circ} \mathrm{ESO}$ del alumno, nivel socioeconómico y nivel académico del tutor principal del adolescente, adquisición de conocimientos teóricos, adquisición de habilidades prácticas y grado de satisfacción del alumno) que posteriormente se analizaron con el programa estadístico SPSS 11.0.

Tras la introducción de los datos, se procedía a realizar una revisión de los mismos de forma aleatoria, para lo que se escogían diferentes cuestionarios al azar y se comprobaba si se habían cometido errores en la trascripción al ordenador. En total se revisaron aleatoriamente un total de 160 cuestionarios (65.04 \% del total). Posteriormente se procedió a realizar el análisis descriptivo de la muestra. Las variables numéricas se resumieron con medias y desviaciones típicas, con los correspondientes intervalos de confianza si precisaron, mientras que las variables cualitativas se expresaron con porcentajes. Para el análisis inferencial que nos permitió evaluar la efectividad o no de la intervención propuesta se empleó ANOVA y la prueba de rango post hoc Tukey (en caso de existir diferencias entre las medias) a fin de poder determinar qué medias difieren entre sí y obtener su correspondiente $\mathrm{p}$ valor.

La investigación se desarrolló en todo momento siguiendo los principios éticos recogidos en la declaración de Helsinki, incluyendo la solicitud de consentimiento informado a todos los alumnos/tutores que se incluirán en el mismo. Todos los registros y el correspondiente consentimiento informado de cada alumnos/tutores se encontrarán debidamente custodiados por el 
investigador principal, estando identificados únicamente por el número asignado de caso, cumpliendo la legislación sobre protección de datos española (Ley orgánica 15/1999 de 13 de Diciembre).

\section{Resultados}

Respecto a los resultados de la primera parte del estudio podemos decir que, tras la realización de la búsqueda bibliográfica se hallaron trabajos que informaban del aumento del empleo de las TIC's en el ámbito de la educación primaria y secundaria (Hernandez, 2011), otros informaban que la integración curricular de las TIC's en la educación tiene un impacto significativo y positivo en términos de "conocimiento-comprensión", "habilidad práctica" y "presentación de habilidad" (Casanova \& Molina, 2013, p. 934) únicamente hallamos un trabajo que implementaban la herramienta $Q R$ en la educación (Bayonet, 2010) pero no se halló ninguno que emplease la herramienta QR como medio para acercar los conocimientos en SVB a los alumnos de $4^{\circ}$ de la ESO.

Los resultados de la segunda parte del trabajo muestran que las características de los alumnos a los que se les realizó la intervención, el $51.4 \%$ pertenecen al sexo masculino y un $48.6 \%$ pertenecen al sexo femenino, siendo la media de edad de mismos de 15.5 años (D.T. $=0.5$ años). En cuanto a la variable resultado académico obtenido en el curso anterior, un $53 \%$ había obtenido un aprobado, un $38 \%$ una nota media de notable y un $9 \%$ una nota media de sobresaliente. Atendiendo a las variables relacionadas con el tutor principal del alumno, la variable nivel económico arrojó que un $21 \%$ de ellos se encontraba desempleado en el momento de la realización de la intervención frente a un $79 \%$ que se encontraba en activo, finalizando el análisis con la variable nivel académico del tutor principal reflejaron que un $18 \%$ no había completado los estudios obligatorios, un $34 \%$ sólo tenía estudios primarios, un $28 \%$ poseía formación profesional y un $20 \%$ había concluido los estudios universitarios. El análisis de las variables adquisición de conocimientos teóricos y adquisición de habilidades prácticas nos permitió conocer la efectividad de la intervención educativa en SVB con el empleo del $\mathrm{QR}$, de tal manera que atendiendo a la variable conocimientos teóricos, observamos aumento en el promedio de los conocimientos en todos los momentos, siendo el momento posterior a intervención inmediata (TEST-POST-INTERV_0) con el momento post-intervención de los 6 meses (TEST-POSTINTERV_6MESES) con una variación de 0.02 puntos el de menor incremento, mientras que el máximo incremento promedio se encontró entre el momento antes de la intervención (TESTPRE_INTERV) con el momento posterior a intervención inmediata (TEST-POST-INTERV_0) con un valor de 7.21 puntos. En la tabla 1 se pueden observar los promedios de conocimientos teóricos adquiridos en todos los momentos junto con su desviación y sus respectivos intervalos de confianza para una probabilidad del $95 \%$. 


\begin{tabular}{|c|c|c|}
\hline & $\begin{array}{c}\text { Media desviación } \\
\text { estándar }\end{array}$ & $\begin{array}{c}\text { Intervalos de confianza } \\
\text { para un } \alpha=0.05\end{array}$ \\
\hline TEST-PRE_INTERV & $1.74 \pm 0.62$ & $(1.66,1.81)$ \\
\hline TEST-POST_INTERV_0 & $8.95 \pm 0.40$ & $(8.90,9.00)$ \\
\hline $\begin{array}{c}\text { TEST- } \\
\text { POST_INTERV_1MES }\end{array}$ & $7.70 \pm 0.63$ & $(7.78,7.68)$ \\
\hline $\begin{array}{c}\text { TEST- } \\
\text { POST_INTERV_3MES }\end{array}$ & $8.59 \pm 0.95$ & $(8.47,8.71)$ \\
\hline
\end{tabular}

Tabla1: Promedio de conocimientos teóricos adquiridos, con su desviación estándar e intervalos de confianza

Para nuestro propósito hemos realizado distintos análisis de varianza de un factor (ANOVA), optando por afirmar que existe influencia estadísticamente significativa de una variable (factor) sobre las valoraciones obtenidas en las pruebas iniciales cuando la probabilidad de error en dicha afirmación sea inferior al $5 \%$ ( $p<0.05$ ), esto es, cuando el intervalo de confianza sea del 95\% (previamente se comprobó que se cumplían todos los requisitos para su aplicación).

De los análisis realizados se demuestra que hay diferencias significativas entre los diferentes momentos de análisis de la variable conocimiento teórico como podemos observar en la tabla 2.

\begin{tabular}{|c|c|c|c|c|c|c|}
\hline $\begin{array}{l}\text { ANÁLISIS DE } \\
\text { VARIANZA }\end{array}$ & & & & & & \\
\hline $\begin{array}{c}\text { Origen de las } \\
\text { variaciones }\end{array}$ & $\begin{array}{l}\text { Suma de } \\
\text { cuadrados }\end{array}$ & $\begin{array}{c}\text { Grad } \\
\text { os de } \\
\text { libert } \\
\text { ad }\end{array}$ & $\begin{array}{l}\text { Promedi } \\
\text { o de los } \\
\text { cuadrado } \\
\text { s }\end{array}$ & $\mathbf{F}$ & $\begin{array}{l}\text { Probabili } \\
\text { dad }\end{array}$ & $\begin{array}{l}\text { Valor } \\
\text { crítico } \\
\text { para F }\end{array}$ \\
\hline Entre grupos & 9407,517848 & 4 & $\begin{array}{c}2351,879 \\
462\end{array}$ & $\begin{array}{c}6110,139 \\
709\end{array}$ & 0,0000 & $\begin{array}{c}2,379193 \\
75\end{array}$ \\
\hline $\begin{array}{l}\text { Dentro de los } \\
\text { grupos }\end{array}$ & 471,5198798 & 1225 & $\begin{array}{c}0,384914 \\
188\end{array}$ & & & \\
\hline Total & 9879,037728 & 1229 & & & & \\
\hline
\end{tabular}

Tabla 2: Análisis de varianza del factor conocimiento teórico

Ante la existencia de estas diferencias significativas, procedimos a realizar un análisis de comparaciones múltiples (prueba post hoc) a través del test de la diferencia honestamente significativa de Tukey (HSD de Tukey) por ser una prueba conservadora que mantiene bajo el error tipo I sacrificando la capacidad de detectar diferencias existentes de una manera más completa. En este sentido y respecto a la variable conocimiento teórico observamos que existían diferencias significativas $(p=0 \%)$ para todos los momentos a excepción de los momentos post-intervención inmediata y la post-intervención de los 6 meses, tal y como se indica en la tabla 3. 


\begin{tabular}{|c|c|c|c|c|}
\hline & Diferencia de medias & $\mathbf{F}$ & Valor de $p$ & SIGNIFICATIVO \\
\hline $\begin{array}{l}\text { TEST- PRE_INTERV } \\
\text { TEST-POST_INTERV_0 }\end{array}$ & $-7,22$ & 23702 & $<0.0000$ & SI \\
\hline $\begin{array}{c}\text { TEST-PRE_INTERV } \\
\text { TEST-POST_INTERV_1MES }\end{array}$ & $-5,96$ & 11347,19 & $<0.0000$ & SI \\
\hline $\begin{array}{c}\text { TEST-PRE_INTERV } \\
\text { TEST-POST_INTERV_3meses }\end{array}$ & $-6,85$ & 8959,33 & $<0.0000$ & SI \\
\hline $\begin{array}{l}\text { TEST-PRE_INTERV } \\
\text { TEST-POST_INTERV_6meses }\end{array}$ & $-7,24$ & 27765,29 & $<0.0000$ & SI \\
\hline $\begin{array}{c}\text { TEST-POST_INTERV_0meses } \\
\text { TEST-POST_INTERV_1mes }\end{array}$ & 1,26 & 703,56 & 8,7395E-97 & SI \\
\hline $\begin{array}{l}\text { TEST-POST_INTERV_0meses } \\
\text { TEST-POST_INTERV_3meses }\end{array}$ & 0,37 & 30,78 & 4,7295E-08 & SI \\
\hline $\begin{array}{l}\text { TEST-POST_INTVEN_0meses } \\
\text { TEST-POST_INTERV_6meses }\end{array}$ & $-0,02$ & 0,32 & $<0.5676$ & NO \\
\hline $\begin{array}{l}\text { TEST-POST_INTERV_1mes } \\
\text { TEST-POST_INTERV_3meses }\end{array}$ & $-0,89$ & 149,91 & 2,9322E-30 & SI \\
\hline $\begin{array}{l}\text { TEST-POST_INTERV_1mes } \\
\text { TEST-POST_INTERV_6meses }\end{array}$ & $-1,27$ & 841,06 & $2,1150 \mathrm{E}-108$ & SI \\
\hline $\begin{array}{l}\text { TEST-POST_INTERV_3mes } \\
\text { TEST-POST_INTERV_6meses }\end{array}$ & $-0,38$ & 36,51 & 3,0009E-09 & SI \\
\hline
\end{tabular}

Tabla 3: Pruebas post hoc: comparaciones múltiples por grupo (en Redacción en castellano).

Atendiendo a la variable adquisición de habilidades prácticas, procedimos a realizar su análisis siguiendo el mismo procedimiento y los resultados fueron los que se muestran a continuación. El momento con menor aumento promedio de resultado fue el momento post intervención a los tres meses (TEST-POST-INTERV_3MESES) con el momento post-intervención de los 6 meses (TESTPOST-INTERV_6MESES) con una variación de 0.43 puntos, mientras que el máximo de diferencia promedio se encontró entre el momento antes de la intervención (TEST-PRE_INTERV) con el momento inmediato a la intervención (TEST-POST-INTERV_6) con un incremento de 7.08 puntos. En la tabla 4 se puede observarse los promedios de conocimientos teóricos adquiridos en todos los momentos junto con su desviación y sus respectivos intervalos de confianza para una probabilidad del $95 \%$. 


\begin{tabular}{|c|c|c|}
\hline & $\begin{array}{c}\text { Media desviación } \\
\text { estándar }\end{array}$ & $\begin{array}{l}\text { Intervalos de confianza para un } \\
\qquad \alpha=0.05\end{array}$ \\
\hline TEST- PRE_INTERV & $1.57 \pm 0.73$ & $(1.48,1.66)$ \\
\hline TEST-POST_INTERV_0 & $6,71 \pm 0.91$ & $(6.59,6.82)$ \\
\hline $\begin{array}{c}\text { TEST- } \\
\text { POST_INTERV_1MES }\end{array}$ & $7,65 \pm 0.55$ & $(7.58,7.72)$ \\
\hline $\begin{array}{c}\text { TEST- } \\
\text { POST_INTERV_3MES }\end{array}$ & $8.22 \pm 0.59$ & $(8.14,8.29)$ \\
\hline $\begin{array}{c}\text { TEST- } \\
\text { POST_INTERV_6MES }\end{array}$ & $8.65 \pm 0.28$ & $(8.61,8.68)$ \\
\hline
\end{tabular}

Tabla 4: Variable adquisición de habilidades prácticas (promedio, desviación estándar e intervalos de confianza).

De los análisis ANOVA realizados para la variable adquisición de habilidades prácticas se demuestra que hay diferencias significativas entre los diferentes momentos de la intervención.

\begin{tabular}{|c|c|c|c|c|c|c|}
\hline \multicolumn{7}{|l|}{$\begin{array}{l}\text { ANÁLISIS DE } \\
\text { VARIANZA }\end{array}$} \\
\hline $\begin{array}{l}\text { Origen de las } \\
\text { variaciones }\end{array}$ & $\begin{array}{l}\text { Suma de } \\
\text { cuadrados }\end{array}$ & $\begin{array}{l}\text { Grados } \\
\text { de } \\
\text { libertad }\end{array}$ & $\begin{array}{l}\text { Promedio de } \\
\text { los } \\
\text { cuadrados }\end{array}$ & $F$ & $\begin{array}{l}\text { Probabili } \\
\text { dad }\end{array}$ & $\begin{array}{l}\text { Valor crítico } \\
\text { para } F\end{array}$ \\
\hline Entre grupos & $\begin{array}{l}8175,68635 \\
9\end{array}$ & 4 & 2043,92159 & $\begin{array}{l}4862,89 \\
576\end{array}$ & 0,0000 & 2,37919375 \\
\hline $\begin{array}{l}\text { Dentro de los } \\
\text { grupos }\end{array}$ & $\begin{array}{l}514,879214 \\
2\end{array}$ & 1225 & 0,420309563 & & & \\
\hline Total & $\begin{array}{l}8690,56557 \\
3\end{array}$ & 1229 & & & & \\
\hline
\end{tabular}

Tabla 5: Análisis de varianza del factor adquisición de habilidades prácticas

Estos datos se reafirman en la tabla 6 que refleja los resultados del test de comparaciones múltiples (test HSD de Tukey), dónde observamos que existían diferencias significativas ( $p=0 \%$ ) para todos los momentos. 


\begin{tabular}{|c|c|c|c|c|}
\hline & $\begin{array}{l}\text { Diferencia de } \\
\text { medias }\end{array}$ & $\mathbf{F}$ & Valor de $p$ & SIGNIFICATIVO \\
\hline $\begin{array}{c}\text { TEST-PRE_INTERV } \\
\text { TEST-POST_INTERV_0 }\end{array}$ & 5,14 & 4879,56 & $\begin{array}{c}3,068 \mathrm{E}- \\
256\end{array}$ & SI \\
\hline $\begin{array}{c}\text { TEST-PRE_INTERV } \\
\text { TEST-POST_INTERV_1MES }\end{array}$ & 6,08 & 10869,77 & $<0.0000$ & SI \\
\hline $\begin{array}{c}\text { TEST-PRE_INTERV } \\
\text { TEST-POST_INTERV } \\
\text { _3meses }\end{array}$ & 6,65 & 12342,81 & $<0.0000$ & SI \\
\hline $\begin{array}{c}\text { TEST- PRE_INTERV } \\
\text { TEST-POST_INTERV } \\
\text { _6meses }\end{array}$ & 7,08 & 20298.87 & $<0.0000$ & SI \\
\hline $\begin{array}{c}\text { TEST-POST_ INTERV } \\
\text { _Omeses }\end{array}$ & 0,94 & 195,67 & $1,25 E-37$ & SI \\
\hline $\begin{array}{c}\text { TEST-POST_INTERV_1mes } \\
\text { TEST-POST_INTERV }\end{array}$ & & & & \\
\hline _Omeses & 1,51 & 484,79 & $4,0279 E-75$ & SI \\
\hline TEST-POST_INTERV_3meses & & & & \\
\hline $\begin{array}{l}\text { TEST-POST_INTVEN_0meses } \\
\text { TEST-POST_INTERV_6meses }\end{array}$ & 1,94 & 1012,15 & $2,784 \mathrm{E}-121$ & SI \\
\hline $\begin{array}{l}\text { TEST-POST_INTERV_1mes } \\
\text { TEST-POST_INTERV_3meses }\end{array}$ & 0,57 & 472,69 & $7,1436 \mathrm{E}-74$ & SI \\
\hline $\begin{array}{l}\text { TEST-POST_INTERV_1mes } \\
\text { TEST-POST_INTERV_6meses }\end{array}$ & 0,99 & 633,04 & $2,6984 \mathrm{E}-90$ & SI \\
\hline $\begin{array}{l}\text { TEST-POST_INTERV_3mes } \\
\text { TEST-POST_INTERV_6meses }\end{array}$ & 0,43 & 105,09 & $1,7921 \mathrm{E}-22$ & SI \\
\hline
\end{tabular}

Para finalizar con los resultados obtenidos diremos que evaluación global de la intervención ha obtenido en el $99 \%$ de los alumnos su valor máximo, la organización de la misma es valorada por un $95.20 \%$ de los alumnos con el máximo valor posible y un $98.6 \%$ valora la actividad formativa (intervención) con la máxima puntuación.

\section{Discusión}

De acuerdo con los resultados obtenidos tras la búsqueda bibliográfica, hallamos diferentes trabajos que trataban de la importancia de intervenciones en educación sanitaria en SVB, indicando explícitamente la necesidad de elaborar o mejorar estrategias orientadas a disminuir los tiempos de respuesta tras una PCR hasta la desfibrilación precoz y a enseñar las maniobras básicas de RCP a la población (Peña, 2013) pues una instauración de maniobras de RCP por las personas que han 
presenciado el paro aumenta en siete veces las posibilidades de supervivencia (Álvarez, Alvarez, \& Rodríguez, 2001; Sasson, Rogers, Dahl, \& Kellermann, 2009; Berg, y otros, 2010; Travers, y otros, 2010) llegando a demostrar que una demora en la asistencia de un minuto decrementaba en un $10 \%$ la posibilidad de supervivencia y tras 10 minutos sin atención, las posibilidades de supervivencia eran mínimas. (Coma, Garcia , Ruano, Loma, Malpartida, \& Rodriguez, 2009). En cambio apenas se encontraron estudios que analicen intervenciones de educación en RCP en poblaciones comprendidas entre 15-16 años con TIC's (Marchiori, Ferrer, Fernández, Povar, Suberviola, \& Giménez, 2012) aunque si se hallaron estudios de intervenciones en educacion en RCP, aunque empleando procedimientos tradicionales de educación. (Miró, Escalada, Jimenez-Fábrega, Diaz, Sanclemente, \& Gómez, 2012; Gracia, Ramas, Malo, Sancho, \& Gracia, 2012).

Atendiendo al empleo de las TIC's en el ámbito de la educación secundaria hallamos estudios que informaban de la extensión del empleo de las mismas en los últimos años (Hernandez, 2011) encontrado ya evidencias en el empleo de TIC's como herramienta de intervención para modificaciones de hábitos y tornarlos a comportamiento saludables, pero son menos los estudios que analizan el empleo de los códigos QR (Bayonet, 2010; Casanova \& Molina, 2013) en el campo de la educación, aun sabiendo que nos proporcionan información inmediata, son un gran recurso para el aprendizaje y motivan a los alumnos a la vez que les permite ejercitar sus habilidades (Casanova \& Molina, 2013).

No hallamos trabajo alguno que hubiese empleado la herramienta QR para realizar una intervención educativa en SVB en alumnos de $4^{\mathrm{a}}$ de ESO en términos de mejora de conocimientos teóricos y habilidades prácticas

Atendiendo a los resultados obtenidos en la segunda parte del estudio diremos que la distribución por sexo de nuestra muestra de alumnos no difiere de la distribución por sexto del total de alumnos escolarizados en secundaria en España, la variable nivel académico del tutor principal y la variable nivel socioeconómico del tutor principal presentan valores semejantes a los que tienen el resto de la población española según datos facilitados por el Instituto Nacional de Estadística (INE) de España en su publicación de Anuario estadístico de España 2016 (Instituto Nacional de Estadistica, 2016)

En nuestro estudio se logra demostrar que es efectiva una intervención educativa en SVB en alumnos de $4^{\mathrm{a}}$ de ESO en la que se utiliza la herramienta QR como medio soporte de la misma. No obstante a la hora de realizar esta intervención sanitaria, nos encontramos algunas limitaciones, las cuales fueron analizadas y se plantearon soluciones para las mismas. Así podemos señalar:

1. No posibilidad de controlar y mantener las limitaciones de la propia intervención. Ello lo solucionaremos buscando un equilibrio entre las necesidades de los alumnos y la estandarización que requiere el procedimiento. 
2. No controlar factores extraños como la historia de los sujetos (cansancio, distracción, aburrimiento, su maduración). Para solucionarlo realizamos las intervenciones sin unir diferentes cursos, con lo que garantizamos el máximo de homogeneidad del grupo.

3. No controlamos factores del entorno: misma hora, mismas condiciones. Como solución se ha planteado la realización del $90 \%$ de las intervenciones a la misma hora y en las condiciones más semejantes.

4. No controlamos los eventos que se puedan producir entre las mediciones pre y pos test que pueden afectar a las variables dependientes (campañas informativas que se realicen paralelamente).

5. No posibilidad evaluar directamente las habilidades adquiridas en alumnos que presenten algún tipo de discapacidad que les impida realiza un masaje cardiaco efectivo. Ello lo solucionaremos evaluándoselas de manera indirecta, a través de un tercero (monitor) que las realizará siguiendo las instrucciones que dichos alumnos le indiquen.

\section{Conclusiones}

Se puede concluir que la intervención educativa en Soporte Vital Básico empleando como herramienta de apoyo los códigos QR dirigido a alumnos de $4^{\circ}$ de ESO ha resultado efectiva. Por lo que el enfoque habitual del tema de las nuevas tecnologías y la educación como empleo exclusivo de aspectos didácticos debe ser sustituido por un enfoque en el cual las TIC's más que como un medio de recursos del docente se consideren como herramientas que están cambiando el mundo para el que educamos niños y jóvenes. Concretamente la herramienta $Q R$ nos proporciona información inmediata, nos sirve como recurso de aprendizaje y permiten motivar a los alumnos a la vez que les permite ejercitar sus habilidades.

Las consecuencias de esta intervención a medio y largo plazo influirá positivamente en los alumnos, los cuales serán capaces de identificar una pérdida de conciencia, ausencia de respiración, parada cardiorrespiratoria, así como de alertar a los servicios de urgencias y emergencias a través del 112 ó 061.

De igual manera estos resultados ayudan significativamente a combatir la inequidad en conocimientos en SVB, mejorando así el entorno y las condiciones de vida, promocionando mejora en salud y previniendo la enfermedad y sus complicaciones sin dejar de aportar valor añadido a la institución que lo realiza, sin ser nada desdeñable el hecho de que el empleo de los QR permite tener accesible la información en cualquier momento. Tiene prácticamente coste cero, tanto su generación como lectura, pues existen en el mercado infinitos generadores y lectores para los diferentes dispositivos electrónicos que todos poseemos, tales como teléfonos móviles, tabletas, etc., de acceso 
libre y completamente gratuitos. Por lo que se podría decir que es una herramienta de las TIC's de coste cero.

Esta herramienta nos permite realizar un seguimiento de su empleo, lo que nos facilita posible implementación de mejoras.

\section{Bibliografía}

Abril, C., Tintorer, D., Gironella, T., Bratescu, A., Ortega, M., Pla, A., y otros. (Enero de 2010). Test Raval Sud para medir habilidades de soporte vital básico y desfibrilación en médicos y enfermeras de atención primaria. Atención primaria, 42(1), 7-13. Recuperado el Febrero de 2015, de eLSEVIER: http://www.elsevier.es/es-revista-atencion-primaria-27-articulo-test-ravalsud-medir-habilidades-13146037

Álvarez, J., Alvarez, M., \& Rodríguez, M. (2001). Supervivencia en España de las paradas cardíacas extrahospitalarias. Med. Intensiva. 25(6):236-243. Recuperado el 6 de Octubre de 2014, de www.medintensiva.org/es/pdf/13020578/S300/

Bayonet, L. (21 de Junio de 2010). Aprendizaje Móvil Aplicado en la Educación Usos prácticos-QR code. Recuperado el Enero de 2015, de Academia:

http://www.academia.edu/1051416/Aprendizaje_M\%C3\%B3vil_Aplicado_en_la_Educaci\%C3 \%B3n_Usos_pr\%C3\%A1cticos_QR_Code

Berg, R., Hemphill, R., Abella, S., Aufderheide, T., Cave, D., Hazinski, M., y otros. (2010). Part 5: Adult basic life support 2010 American Heart Association guidelines for cardiopulmonary resuscitation and emergency cardiovascular care. Recuperado el Noviembre de 2014, de Circulation, 122(18 suppl 3), S685-S705.: http://circ.ahajournals.org/content/122/18_suppl_3/S685.short

Carrillo-Larco, R., \& Curioso, W. (2013). Oportunidades del código QR para diseminar información en salud. Revista Peruana de Medicina Experimental y Salud Publica, 30(2), 362-363.

Recuperado el Enero de 2015, de Scielo: http://www.scielo.org.pe/pdf/rins/v30n2/a42v30n2.pdf

Casanova, G., \& Molina, J. (2013). Implementación de códigos QR en materiales docentes. Recuperado el Febrero de 2015, de Universidad de Alicante: http://rua.ua.es/dspace/bitstream/10045/43301/1/2013-XI-Jornadas-Redes-68.pdf

Coma, I., Garcia , L., Ruano, M., Loma, A., Malpartida, F., \& Rodriguez, J. (Agosto de 2009). Guías de actuación clínica de la Sociedad Española de Cardiología en resucitación cardiopulmonar. Recuperado el Octubre de 2014, de Revista española de cardiología. 52(8):547-647: http://www.revespcardiol.org/es/guias-actuacion-clinica-sociedad-espanola/articulo/152/

Consejería de Salud. (17 de 10 de 2012). Plan de Atención a la Accidentabilidad 2007-2012. Recuperado el Febrero de 2015, de Junta de Andalucia. Consejeria de Salud: http://www.juntadeandalucia.es/salud/channels/temas/temas_es/P_2_ANDALUCIA_EN_SAL UD_PLANES_Y_ESTRATEGIAS/plan_accidentabilidad/plan_accidentabilidad?idioma=es\&pe 
rfil=org\&tema=/temas_es/P_2_ANDALUCIA_EN_SALUD_PLANES_Y_ESTRATEGIAS/plan_ accidentabilidad/\&con

Gracia, S., Ramas, R., Malo, E., Sancho, A., \& Gracia, J. \&. (2012). El niño en la cadena de supervivencia ¿un interviniente útil? Estudio sobre un escenario de simulación. Revista Española de Pediatría, 3(68), 226-233.

Hernandez, J. (2011). Experiencias educativas en la aulas del siglo XXI. Innovación con TIC. Recuperado el Febrero de 2015, de Fundación Telefónica: http://www.fundaciontelefonica.com/arte_cultura/publicaciones-listado/pagina-itempublicaciones/?itempubli $=87$

Instituto Nacional de Estadistica. (2016). Anuario Estadistico de España. Recuperado el 2016, de Produccion y servicios: http://www.ine.es/prodyser/pubweb/anuarios_mnu.htm Junta de Andalucía. Consejería de Igualdad, Salud y Políticas sociales. (2010). Informarse es salud. Recuperado el Junio de 2014, de youtube: http://www.youtube.com/watch?v=ykXVYgGrzds. Junta de Andalucia. Consejería de Salud. (9 de Septiembre de 2012). Portal de la consejería de Salud. Programa Forma Joven. Recuperado el 24 de Septiembre de 2014, de http://www.juntadeandalucia.es/salud/channels/temas/temas_es/C_3_NUESTRA_SALUD/C_ 1_Vida_sana/Adolescencia/Forma_Joven/programa_forma_joven?perfil=ciud\&desplegar=/te mas_es/C_3_NUESTRA_SALUD/\&idioma=es\&tema=/temas_es/C_3_NUESTRA_SALUD/C_ 1_Vida_sana/Adolesce

Marchiori, E., Ferrer, G., Fernández, B., Povar, J., Suberviola, J., \& Giménez, A. (2012). Instrucción en maniobras de soporte vital básico mediante juegos a escolares comparación de resultados frente a grupo control. Revista de la Sociedad Española de Medicina de Urgencias y Emergencias, 24(6), 433-437.

Ministerio de Industria, Energia y Turismo. (s.f.). Encuesta de satisfacción. Recuperado el Marzo de 2015, de Ministerio de industris, Energía y Turismo.:

http://www.minetur.gob.es/PortalAyudas/seguridadminera/Justificacion/2013/Convocatoria\%2 02013/Actuaciones\%20de\%20formaci\%C3\%B3n\%20en\%20seguridad\%20minera/Modelo_en cuesta_satisfaccion_actividad_formativa.doc.

Ministerio de Sanidad y Política Social. (7 de Septiembre de 2007). Ministerio de Sanidad y Política Social. Recuperado el 25 de Octubre de 2014, de Desfibrilación Semiautomática en España. Informe:

http://www.msssi.gob.es/organizacion/sns/planCalidadSNS/docs/Informe_uso_Desfibriladores _sep_07.pdf

Miró, O., Escalada, X., Jimenez-Fábrega, X., Diaz, N., Sanclemente, G., \& Gómez, X. S. (2012). Programa de Reanimación Cardiopulmomnar orientado a centros de enseñanza secundaria (PROCESS): conclusiones tras cinco años de experiencia. Emergencias(20), 229-36.

Peña, S. (Agosto de 2013). Supervivencia extrahospitalaria tras una parada cardiorespiratoria en España: Una revisión de la literatura. Recuperado el octubre de 2014, de Dialnet: http://dialnet.unirioja.es/servlet/articulo?codigo $=4260432$ 
Perales, Jimenez, González, Álvarez, Medicna, Ortega, y otros. (Agosto de 2003). La desfibrilación temprana: conclusiones y recomendaciones del I Foro de Expertos en Desfibrilación Semiautomática. Recuperado el 25 de Noviembre de 2014, de Med Intensiva: http://www.medintensiva.org/es/la-desfibrilacion-temprana-conclusionesrecomendaciones/articulo/13051236/

Sasson, C., Rogers, M., Dahl, J., \& Kellermann, A. (1 de Septiembre de 2009). Predictors of survival from out-fo-hospitaol cardiac arrest a systematic review and meta-analysis. Recuperado el 16 de Noviembre de 2014, de Circulation: Cardiovascular Quality and Outcomes, 3 (1), 63-81: :http://circoutcomes.ahajournals.org/content/3/1/63.short

SEMICYUC. (s.f.). Plan Nacional RCP. Guías 2010 para la resucitación cardiopulmonar (RCP) del Consejo Europeo de Resucitación. Recuperado el Noviembre de 2014, de Semicyuc: http://www.semicyuc.org/sites/default/files/resumen_guias_erc_2010.pdf

Servicio Andaluz de Salud. (13 de Enero de 2015). Plan andaluz de urgencias y emergencias. Última revisión: sin fecha. Recuperado el Febrero de 2015, de Junta de Andalucia. Consejeria de Salud. Servicio Andaluz de Salud: http://www.juntadeandalucia.es/servicioandaluzdesalud/principal/documentosacc.asp?pagina =pr_ges_cal_PlanAndUrgEmerg

Travers, A., Rea, T., Bobrow, B., Edelson, D., Breg, R., Sayre, M., y otros. (2010). Part 4: CPR overview 2010 American Heart Association guidelines for cardiopulmonary resuscitation and emergency cardiovascular care. Recuperado el Noviembre de 2014, de Circulation, 122(18 suppl 3), S676-S684: http://circ.ahajournals.org/content/122/18_suppl_3/S676.short

Wave, D. (2013). Answer to yourquestions about the QR code. Recuperado el Enero de 2015, de qrcode: http://www.qrcode.com/en/ 


\section{Anexos}

\section{Anexo 1. Cuestionario teórico pre y post -intervención}

\section{AnEXo I. CUESTIONARIO TEÓRICO PRE Y POST -INTERVENCIÓN.}

\section{Cuestionario}

\begin{tabular}{|c|c|}
\hline Fecha de realización de la encuesta & № de orden en la lista oficial de clase \\
\hline$\overline{\text { Sexo }}$ & $\square$ Hombre $\square$ Mujer \\
\hline Edad & años \\
\hline Nota Final 3 ESO & 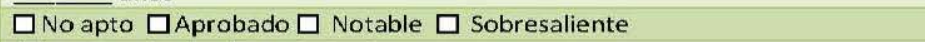 \\
\hline Tutor principal & $\square$ Desempleado $\square$ Trabajando \\
\hline Nivel académico tutor principal & $\begin{array}{l}\square \text { Sin estudios } \\
\square \text { Estudios primarios } \\
\square \text { Formación profesional } \\
\square \text { Estudios universitarios }\end{array}$ \\
\hline \multicolumn{2}{|c|}{$\begin{array}{l}\text { CUESTIONARIO PRE-INTERVENCIÓN } \\
\text { Marque con una cruz la respuesta que considere correcta. }\end{array}$} \\
\hline $\begin{array}{l}\text { 1.- ¿Cuál es la profundidad de las } \\
\text { compresiones torácicas) }\end{array}$ & $\begin{array}{l}\square 3 \text { pulgadas } \\
\square 2.5 \text { pulgadas } \\
\square 3 \text { centimetros } \\
\square 5 \text { centimetros }\end{array}$ \\
\hline $\begin{array}{l}\text { 2.- La secuencia de la cadena PAS } \\
\text { es }\end{array}$ & $\begin{array}{l}\square \text { Proteger-Avisar-Socorrer } \\
\square \text { Preguntar-Auxiliar-Salvar } \\
\square \text { Posición-Auxiliar-Socorrer } \\
\square \text { Proteger-Avisar-Salvar }\end{array}$ \\
\hline $\begin{array}{l}\text { 3.- Las compresiones torácicas } \\
\text { deben ser al menos de }\end{array}$ & $\begin{array}{l}\square 90 \text { por minuta } \\
\square 150 \text { por minuto } \\
\square 100 \text { por minuto } \\
\square 85 \text { por minuta }\end{array}$ \\
\hline $\begin{array}{l}\text { 4.- El ciclo de compresiones y } \\
\text { ventilaciones en un adulto es }\end{array}$ & $\begin{array}{l}\square 30: 2 \\
\square 15: 2 \\
\square 2: 30 \\
\square 2: 15\end{array}$ \\
\hline $\begin{array}{l}\text { 5.- El método para abrir la vía aérea } \\
\text { con el fin de realizar las } \\
\text { ventilaciones es }\end{array}$ & $\begin{array}{l}\square \text { Maniobra frente - menton } \\
\square \text { Estircación mandibular } \\
\square \text { Maniobra mentón-frente } \\
\square \text { Alineación cuello }\end{array}$ \\
\hline $\begin{array}{l}\text { 6.- Para pedir auxilio el número de } \\
\text { emergencia es }\end{array}$ & $\begin{array}{l}\square 112 \\
\square 061 \\
\square 112 \text { y } 061 \\
\square 210\end{array}$ \\
\hline $\begin{array}{l}\text { 7.- ¿Cuál es la posición correcta en } \\
\text { que debemos colocar a un paciente } \\
\text { inconsciente que necesite cuidados } \\
\text { de reanimación cardio-pulmonar? }\end{array}$ & $\begin{array}{l}\square \text { Posición lateral de seguridad } \\
\square \text { Trendelemburg } \\
\square \text { Decúbito supino con la cabeza en hiperextensión } \\
\square \text { Decúbito supino con la cabeza ladeada }\end{array}$ \\
\hline $\begin{array}{l}\text { 8.- A un accidentado se le practica } \\
\text { una R.C.P. (reanimación } \\
\text { cardiopulmonar). Indique en estos } \\
\text { casos, en qué orden hay que actuar: }\end{array}$ & $\begin{array}{l}\square \text { RCP por el testigo, reconocimiento precaz de la emergencia y llamar } \\
\text { pidiendo ayuda, desfibrilación, soporte vital avanzado y cuidados post- } \\
\text { reanimación } \\
\square \text { Soporte vital avanzado y cuidados post-reanimación, RCP por el testigo, } \\
\text { reconocimiento precoz de la emergencia y llamar pidiendo ayuda, } \\
\text { desfibrilación } \\
\square \text { Reconocimiento precoz de la emergencia y llamar pidiendo ayuda, RCP por } \\
\text { el testigo, desfibrilación, soporte vital avanzado y cuidados post-reanimación } \\
\square \text { Reconocimiento precoz de la emergencia y llamar pidiendo ayuda, } \\
\text { desfibrilación, RCP por el testigo, soporte vital avanzado y cuidados post- } \\
\text { reanimación }\end{array}$ \\
\hline
\end{tabular}




\section{Anexo 2. Check-list de habilidades psicomotoras}

\begin{tabular}{l|l} 
Check-list de habilidades psicomotoras & $\mathbf{N}^{\mathrm{o}}$ de orden
\end{tabular}

19 parte : valoración inicial

\begin{tabular}{|c|c|c|c|c|}
\hline $\begin{array}{l}\text { Aproximación y /o actuación } \\
\text { segura: identifica y elimina } \\
\text { peligro }\end{array}$ & $\begin{array}{l}\text { 1. No } \\
\text { identifica }\end{array}$ & $\begin{array}{l}\text { 2. Identifica, } \\
\text { no elimina. }\end{array}$ & 3. Elimina & 9. No valorable \\
\hline \multicolumn{5}{|c|}{ ETAPA 2: Comprobar si responde (estado de conciencia) y pedir ayuda } \\
\hline Comprobar respuesta : gritar & \multicolumn{2}{|l|}{ 1. No realizado } & \multicolumn{2}{|l|}{ 2. Realizado } \\
\hline Comprobar respuesta : agitar & $\begin{array}{l}\text { 1. Realizado } \\
\text { peligrosamen } \\
\text { te }\end{array}$ & 2. No realizado & $\begin{array}{l}3 . \\
\text { Realización } \\
\text { incorrecta }\end{array}$ & $\begin{array}{l}\text { 4. Realización } \\
\text { correcta }\end{array}$ \\
\hline $\begin{array}{l}\text { Alertar gritando ayuda (sean } 1 \\
\text { o } 2 \text { reanimadores) }\end{array}$ & \multicolumn{2}{|l|}{ 1. No realizado } & \multicolumn{2}{|l|}{ 2. Realizado } \\
\hline \multicolumn{5}{|l|}{ ETAPA 3: Vía aérea y respiración } \\
\hline Apertura inicial de la vía aérea & $\begin{array}{l}\text { 1. No } \\
\text { intentada }\end{array}$ & \multicolumn{2}{|l|}{ 2. Incorrecta } & 3. Correcta \\
\hline $\begin{array}{l}\text { Inspección visual de la cavidad } \\
\text { bucal y despejar la vía aérea) }\end{array}$ & $\begin{array}{l}\text { 1. No elimina } \\
+\begin{array}{c}\text { Técnica } \\
\text { peligrosa }\end{array}\end{array}$ & $\begin{array}{l}\text { 2. No elimina }+ \\
\text { No técnica } \\
\text { peligrosa }\end{array}$ & $\begin{array}{l}\text { 3. Elimina } \\
+ \text { Técnica } \\
\text { peligrosa }\end{array}$ & $\begin{array}{l}\text { 3. Elimina + } \\
\text { No técnica } \\
\text { peligrosa }\end{array}$ \\
\hline Comprobación inicial si respira & $\begin{array}{l}\text { 1. No } \\
\text { realizada }\end{array}$ & \multirow{2}{*}{\multicolumn{2}{|c|}{\begin{tabular}{l|l} 
& Incorrecta \\
ación transmitida y tiempo de lla
\end{tabular}}} & 4. Correcta \\
\hline \multicolumn{3}{|c|}{ ETAPA 4: Llamada telefónica al 112 o 061 (información transmitida y tiempo de llamada) } & & \\
\hline $\begin{array}{l}\text { Momento de llamada al 112/ } \\
061\end{array}$ & $\begin{array}{l}\text { 1. No } \\
\text { realizado }\end{array}$ & $\begin{array}{l}2 . \\
\text { Inadecuado }\end{array}$ & 3. Adecuado & \multirow{2}{*}{$\begin{array}{l}\text { Tiempo de llamada } \\
\text { al } 112 \\
\text { (desde el inicio de } \\
\text { la prueba hasta que } \\
\text { empieza a hablar) } \\
\text {......................segundos. }\end{array}$} \\
\hline $\begin{array}{l}\text { Información dada al } 112 \text { o } 061 \\
\text { a) Qué ocurre } \\
\text { b) Localización del suceso } \\
\text { c) No exceda de } 30 \text { segundos }\end{array}$ & 1. Inadecuada & 2. Adecuada & $\begin{array}{l}\text { 9. No } \\
\text { procede } \\
\text { valorar por no } \\
\text { Ilamada }\end{array}$ & \\
\hline \multicolumn{5}{|l|}{ ETAPA 5: Ventilaciones iniciales } \\
\hline $\begin{array}{l}2 \text { ventilaciones iniciales } \\
\text { efectivas } \\
\text { (las que no van seguidas de } \\
\text { compresiones) }\end{array}$ & $\begin{array}{l}\text { 1. No } \\
\text { realizada }\end{array}$ & \multicolumn{2}{|c|}{$\begin{array}{l}\text { 2. Incorrecta (un no diferente } \\
\text { a } 2 \text { ventilaciones efectivas con } \\
\text { un máximo } 5 \text { intentos) }\end{array}$} & $\begin{array}{l}\text { 3. Correcta. ( } 2 \text { y no } \\
\text { más ventilaciones } \\
\text { efectivas de máximo } \\
5 \text { intentos) }\end{array}$ \\
\hline \multicolumn{5}{|c|}{ ETAPA 6: Comprobación inicial de signos de circulación } \\
\hline Apertura inicial de la vía aérea & $\begin{array}{l}\text { 1. No } \\
\text { intentada }\end{array}$ & \multicolumn{2}{|l|}{ 2. Incorrecta } & 3. Correcta \\
\hline $\begin{array}{l}\text { Comprobación inicial de signos } \\
\text { de circulación : Respiración y } \\
\text { pulso carotideo }\end{array}$ & $\begin{array}{l}\text { 1. No } \\
\text { intentada }\end{array}$ & $\begin{array}{l}2 . \\
\text { Incorrecta }\end{array}$ & $\begin{array}{l}\text { 3. Incompleta } \\
\text { Marcar la } \\
\text { realizada bien: } \\
\text { Respiración } \\
\square \text { Pulso carotideo }\end{array}$ & 4. Correcta \\
\hline $\begin{array}{l}\text { Comprobado pulso carotideo } \\
\text { tras las } 2 \text { ventilaciones } \\
\text { iniciales }\end{array}$ & $\begin{array}{l}\text { 1.No } \\
\text { comprobado }\end{array}$ & \multicolumn{2}{|c|}{ 2. Sí comprobado } & $\begin{array}{l}\text { 3. No hechas } \\
\text { ventilaciones }\end{array}$ \\
\hline
\end{tabular}

Si el rescatador no utiliza el DEA , ir etapa 18. 
Check-list de habilidades psicomotoras $\quad \mathbf{N}^{\circ}$ de orden

2arte : secuencia de shocks 1 a 3 con desfibrilador

\begin{tabular}{|c|c|c|c|c|c|c|c|c|}
\hline Encender el DEA & \multirow{2}{*}{\multicolumn{2}{|c|}{$\begin{array}{l}\text { 1. No realizado } \\
\text { 1. Electrodos no } \\
\text { colocados al } \\
\text { paciente o no } \\
\text { conectados al } \\
\text { aparato. }\end{array}$}} & \multicolumn{6}{|l|}{ 2. Realizado } \\
\hline \multirow[t]{2}{*}{$\begin{array}{l}\text { Localización } \\
\text { /conexión de los } \\
\text { electrodos del } \\
\text { desfibrilador }\end{array}$} & & & $\begin{array}{l}\text { 2. Ambos } \\
\text { electrodos } \\
\text { fuera del } \\
\text { área. }\end{array}$ & \multicolumn{3}{|c|}{$\begin{array}{l}\text { 3. Un } \\
\text { electrodo } \\
\text { sobrepasa el } \\
\text { borde y el } \\
\text { otro } \\
\text { completamen } \\
\text { te fuera del } \\
\text { área. }\end{array}$} & \multicolumn{2}{|c|}{$\begin{array}{l}\text { 4. Un electrodo } \\
\text { completamente dentro y el } \\
\text { otro completamente fuera } \\
\text { del área. }\end{array}$} \\
\hline & \multicolumn{2}{|c|}{$\begin{array}{l}\text { 5. Ambos } \\
\text { electrodos } \\
\text { sobrepasan el } \\
\text { borde del área. }\end{array}$} & \multicolumn{3}{|c|}{$\begin{array}{l}\text { 6. Un electrodo } \\
\text { completamente dentro } \\
\text { y el otro sobrepasa el } \\
\text { borde del área. }\end{array}$} & \multicolumn{3}{|c|}{$\begin{array}{l}\text { 7. Ambos electrodos } \\
\text { completamente dentro del área }\end{array}$} \\
\hline $\begin{array}{l}\text { Se fijan (pegan) los } \\
\text { electrodos a la piel } \\
\text { del tórax }\end{array}$ & \multicolumn{2}{|c|}{ 1.No se fijan } & 2. Sí se fijan & \multicolumn{5}{|c|}{$\begin{array}{l}\text { 3. NO es posible valorar } \\
\text { La fijación. }\end{array}$} \\
\hline \multicolumn{9}{|c|}{ (El controlador provoca el primer contacto con el maniquí de una forma estandarizada) } \\
\hline $\begin{array}{l}\text { ETAPA } 8 \\
\text { Interferencia en el } \\
\text { análisis del DEA : } \\
\text { orden de apartarse. }\end{array}$ & \multicolumn{2}{|c|}{$\begin{array}{l}\text { 1. El reanimador NO } \\
\text { PIDE al controlador } \\
\text { que se aparte de la } \\
\text { víctima. }\end{array}$} & \multicolumn{5}{|c|}{$\begin{array}{l}\text { 2. El reanimador } S|P| D E \text { al } \\
\text { controlador que se aparte de la } \\
\text { victima }\end{array}$} & 9. No valorable \\
\hline \multirow{2}{*}{$\begin{array}{l}\text { ETAPA } 9 \\
\text { Comprobación } \\
\text { visual Y verbal de } \\
\text { "nadie toque al } \\
\text { paciente" durante } \\
\text { el analisis del DEA } \\
\text { (1er shock) }\end{array}$} & \multicolumn{2}{|c|}{$\begin{array}{c}\text { VISUAL } \\
\text { (giro cabeza) }\end{array}$} & \multicolumn{2}{|c|}{ 1. No realizada } & \multicolumn{3}{|c|}{ 2. Si realizada } & $\begin{array}{l}\text { 9. No procede } \\
\text { valorar }\end{array}$ \\
\hline & \multicolumn{2}{|c|}{ VERBAL } & \multicolumn{2}{|c|}{ 1. No realizada } & \multicolumn{3}{|c|}{ 2. Si realizada } & $\begin{array}{l}\text { 9. No procede } \\
\text { valorar }\end{array}$ \\
\hline \multicolumn{9}{|c|}{ EI DEA avisa: 1 er shock aconsejado } \\
\hline \multirow{2}{*}{$\begin{array}{l}\text { ETAPA } 10 \\
\text { Seguridad ( "nadie } \\
\text { toque al paciente") } \\
\text { antes de pulsar el } \\
\text { botón ( shock1) }\end{array}$} & $\begin{array}{l}\text { VISUAL } \\
\text { (giro } \\
\text { cabeza) } \\
\end{array}$ & $\begin{array}{l}\text { 1. No } \\
\text { pulsa } \\
\text { botón }\end{array}$ & \multicolumn{2}{|c|}{\begin{tabular}{|l|} 
2. No \\
comprobación \\
Si pulsa botón
\end{tabular}} & \multicolumn{3}{|c|}{$\begin{array}{l}\text { 3. Sí comprobación } \\
\text { Si pulsa botón }\end{array}$} & $\begin{array}{l}\text { 9. No procede } \\
\text { valorar }\end{array}$ \\
\hline & VERBAL & $\begin{array}{l}\text { 1. No } \\
\text { pulsa } \\
\text { botón }\end{array}$ & \multicolumn{2}{|c|}{$\begin{array}{l}\text { 2. No } \\
\text { comprobación } \\
\text { Si pulsa botón }\end{array}$} & \multicolumn{3}{|c|}{$\begin{array}{l}\text { 3. Sí comprobación } \\
\text { Si pulsa botón }\end{array}$} & $\begin{array}{l}\text { 9. No procede } \\
\text { valorar }\end{array}$ \\
\hline \multirow{2}{*}{$\begin{array}{l}\text { ETAPA } 11 \\
\text { Comprobación } \\
\text { visual Y verbal de } \\
\text { "nadie toque al } \\
\text { paciente" durante } \\
\text { el analisis del DEA } \\
\text { (shock 2) }\end{array}$} & $\begin{array}{l}\text { VISUAL } \\
\text { (giro } \\
\text { cabeza) }\end{array}$ & \multicolumn{3}{|c|}{ 1. No realizada } & \multicolumn{3}{|c|}{ 2. Si realizada } & $\begin{array}{l}\text { 9. No procede } \\
\text { valorar }\end{array}$ \\
\hline & VERBAL & \multicolumn{3}{|c|}{ 1. No realizada } & \multicolumn{3}{|c|}{ 2. Sí realizada } & $\begin{array}{l}\text { 9. No procede } \\
\text { valorar }\end{array}$ \\
\hline
\end{tabular}




\begin{tabular}{|c|c|c|c|c|c|c|}
\hline \multirow{2}{*}{$\begin{array}{l}\text { ETAPA } 12 \\
\text { Seguridad ( "nadie } \\
\text { toque al paciente") } \\
\text { antes de pulsar el } \\
\text { botón ( shock2) }\end{array}$} & $\begin{array}{l}\text { VISUAL } \\
\text { (giro } \\
\text { cabeza) }\end{array}$ & $\begin{array}{l}\text { 1. No } \\
\text { pulsa } \\
\text { botón }\end{array}$ & \multicolumn{2}{|c|}{\begin{tabular}{|l|} 
2. No \\
comprobación \\
Si pulsa botón
\end{tabular}} & $\begin{array}{l}\text { 3. Si comprobación } \\
\text { Si pulsa botón }\end{array}$ & $\begin{array}{l}\text { 9. No procede } \\
\text { valorar }\end{array}$ \\
\hline & VERBAL & $\begin{array}{l}\text { 1. No } \\
\text { pulsa } \\
\text { botón }\end{array}$ & \multicolumn{2}{|c|}{$\begin{array}{l}\text { 2. No } \\
\text { camprobación } \\
\text { Si pulsa botón }\end{array}$} & $\begin{array}{l}\text { 3. Sí comprobación } \\
\text { Si pulsa botón }\end{array}$ & $\begin{array}{l}\text { 9. No procede } \\
\text { valorar }\end{array}$ \\
\hline \multirow{2}{*}{$\begin{array}{l}\text { ETAPA } 13 \\
\text { Comprobación } \\
\text { visual Y verbal de } \\
\text { "nadie toque al } \\
\text { paciente" durante } \\
\text { el analisis del DEA } \\
\text { (3er shock) }\end{array}$} & $\begin{array}{l}\text { VISUAL } \\
\text { (giro } \\
\text { cabeza) }\end{array}$ & \multicolumn{3}{|c|}{ 1. No realizada } & 2. Si realizada & $\begin{array}{l}\text { 9. No procede } \\
\text { valorar }\end{array}$ \\
\hline & VERBAL & \multicolumn{3}{|c|}{ 1. No realizada } & 2. Sí realizada & $\begin{array}{l}\text { 9. No procede } \\
\text { valorar }\end{array}$ \\
\hline \multicolumn{7}{|c|}{$\begin{array}{l}\text { EI DEA avisa: } 32 \text { shock aconsejado } \\
\text { El controlador provoca contacto con el maniquí de una forma estandarizada }\end{array}$} \\
\hline $\begin{array}{l}\text { ETAPA } 14 \\
\text { Comprobación de la } \\
\text { seguridad del } \\
\text { controlador } \\
\text { (inmediatamente antes } \\
\text { del 3er schock) }\end{array}$ & \multicolumn{3}{|c|}{$\begin{array}{l}\text { 1. El reanimador NO } \\
\text { PIDE al controlador que } \\
\text { se aparte de la víctima. }\end{array}$} & \multicolumn{2}{|c|}{$\begin{array}{l}\text { 2. El reanimador SI PIDE al } \\
\text { controlador que se aparte } \\
\text { de la victima }\end{array}$} & valorable \\
\hline \multirow{2}{*}{$\begin{array}{l}\text { ETAPA } 15 \\
\text { Seguridad ( "nadie } \\
\text { toque al paciente") } \\
\text { antes de pulsar el } \\
\text { botón ( shock3) }\end{array}$} & $\begin{array}{l}\text { VISUAL } \\
\text { (giro } \\
\text { cabeza) }\end{array}$ & $\begin{array}{l}\text { 1. No } \\
\text { pulsa } \\
\text { botón }\end{array}$ & 2. N & $\begin{array}{l}\text { robación } \\
\text { pulsa botón }\end{array}$ & $\begin{array}{l}\text { 3. Sí comprobación } \\
\text { Si pulsa botón }\end{array}$ & $\begin{array}{l}\text { 9. No procede } \\
\text { valorar }\end{array}$ \\
\hline & VERBAL & $\begin{array}{l}\text { 1. No } \\
\text { pulsa } \\
\text { botón }\end{array}$ & $\begin{array}{r}\text { 2. N } \\
\text { com } \\
\mathrm{Si}\end{array}$ & $\begin{array}{l}\text { robación } \\
\text { pulsa botón }\end{array}$ & $\begin{array}{l}\text { 3. Sí comprobación } \\
\text { Si pulsa botón }\end{array}$ & $\begin{array}{l}\text { 9. No procede } \\
\text { valorar }\end{array}$ \\
\hline \multirow{2}{*}{$\begin{array}{l}\text { ETAPA } 16 \\
\text { Comprobación } \\
\text { visual Y verbal de } \\
\text { "nadie toque al } \\
\text { paciente" durante } \\
\text { el analisis del DEA } \\
\text { (3er shock) }\end{array}$} & $\begin{array}{l}\text { VISUAL } \\
\text { (giro } \\
\text { cabeza) }\end{array}$ & \multicolumn{3}{|c|}{ 1. No realizada } & 2. Si realizada & $\begin{array}{l}\text { 9. No procede } \\
\text { valorar }\end{array}$ \\
\hline & VERBAL & \multicolumn{3}{|c|}{ 1. No realizada } & 2. Si realizada & $\begin{array}{l}\text { 9. No procede } \\
\text { valorar }\end{array}$ \\
\hline \multicolumn{7}{|l|}{ Después de 3 shocks } \\
\hline \multicolumn{7}{|c|}{ ETAPA 17: Comprobación de signos de circulación tras el 3er shock } \\
\hline $\begin{array}{l}\text { Apertura de via } \\
\text { aérea }\end{array}$ & \multicolumn{2}{|c|}{ 1. No intentada } & \multicolumn{3}{|c|}{ 2. Incorrecta } & 3. Correcta \\
\hline $\begin{array}{l}\text { Comprobación } \\
\text { inicial de signos de } \\
\text { circulación: } \\
\text { Respiración y puiso } \\
\text { carotideo }\end{array}$ & \multicolumn{2}{|c|}{ 1. No intentada } & \multicolumn{2}{|c|}{ 2. Incorrecta } & $\begin{array}{l}\text { 3. Incompleta } \\
\text { Marcar la realizada } \\
\text { bien: } \\
\text { II Respiración } \\
\text { a Pulso carotideo }\end{array}$ & 4. Correcta \\
\hline
\end{tabular}


\begin{tabular}{l|l} 
Check-list de habilidades psicomotoras & $\mathbf{N}^{\circ}$ de orden
\end{tabular}

3a parte: secuencia de RCP (resucitación Cardio pulmonar)

\begin{tabular}{|c|c|c|c|c|c|c|c|c|c|}
\hline \multicolumn{10}{|c|}{$\begin{array}{l}\text { ETAPA } 18 \\
\text { Tiempo de inicio de RCP ........ seg } \\
\text { secuencia que incluya ventilación }\end{array}$} \\
\hline \multicolumn{10}{|c|}{ ETAPA 19 Ventilación efectiva } \\
\hline \multicolumn{3}{|c|}{$\begin{array}{l}\text { Ventilaciones efectivas } \\
\text { apreciadas } \\
\text { (las del ler bucle/serie de } \\
\text { ventilaciones que van } \\
\text { seguidas de compresiones) } \\
\text { (se eleva tórax normalmente) }\end{array}$} & \begin{tabular}{|l|} 
1. No \\
realizada
\end{tabular} & $\begin{array}{l}\text { 2. Incorrec } \\
\text { (un no diferer } \\
\text { ventilaciones } \\
\text { máximo de } 5\end{array}$ & $\begin{array}{l}\text { cta } \\
\text { nte a } 2 \\
\text { s efectiva } \\
5 \text { intentos }\end{array}$ & as con un & \multicolumn{2}{|c|}{$\begin{array}{l}\text { 3. Correcta. } \\
\text { (2 y no más ventilaciones } \\
\text { efectivas de máximo de } 5 \\
\text { intentos) }\end{array}$} & $\begin{array}{l}\text { 9. No } \\
\text { comprobable }\end{array}$ \\
\hline \multicolumn{10}{|c|}{$\begin{array}{l}\text { ETAPA 20: Posición de manos y brazos para las compresiones torácicas } \\
\text { (1 minuto a partir de la primera compresión de la RCP que se valora) }\end{array}$} \\
\hline \multicolumn{2}{|c|}{$\begin{array}{l}\text { Búsqueda de la zona de } \\
\text { compresión } \\
\text { (en la primera serie de } \\
\text { compresiones) }\end{array}$} & \multicolumn{3}{|c|}{ 1. No intentada } & \multicolumn{2}{|c|}{ 2. Incorrecta } & & \multicolumn{2}{|c|}{ 3. Correcta } \\
\hline \multicolumn{5}{|c|}{ Número de compresiones peligrosas (en 1 minuto) } & \multicolumn{5}{|c|}{ Inserte № : .................... } \\
\hline \multicolumn{5}{|c|}{ Colocacion de brazos incorrectos (en 1 minuto) } & \multicolumn{5}{|c|}{ Inserte № : .................... } \\
\hline \multicolumn{10}{|c|}{ ETAPA 21 Relación Ventilación / Compresión } \\
\hline $\begin{array}{l}\text { Relación } \\
\text { Compresión / } \\
\text { ventilación } \\
\text { percibida por el } \\
\text { evaluador } \\
\text { durante el } \\
\text { minuto de RCP. } \\
\text { (mirar la primera } \\
\text { serie de } \\
\text { compresiones) }\end{array}$ & \multicolumn{3}{|c|}{$\begin{array}{l}\text { 1. }<13 \\
\text { por cada } \\
\times \text { insuflaciones }\end{array}$} & \multicolumn{2}{|c|}{$\begin{array}{l}\text { 2. }>17 \\
\text { por cada } \\
x \text { insuflaciones }\end{array}$} & \multicolumn{3}{|c|}{$\begin{array}{l}\text { 3. } 13-17 \\
\text { por cada } \\
x \text { insuflaciones }\end{array}$} & $\begin{array}{l}\text { iserte № } \\
\text {..C / .......V }\end{array}$ \\
\hline \multicolumn{10}{|c|}{ ETAPA 22: Compresión (frecuencia : no de compresiones / minuto) } \\
\hline \multirow{2}{*}{\multicolumn{4}{|c|}{$\begin{array}{l}\text { Frecuencia de compresiones } \\
\text { percibida por el evaluador x minuto } \\
\text { (Mirar } 1 \text { minuto a partir de la 1era } \\
\text { compresión) }\end{array}$}} & \multirow{2}{*}{\multicolumn{2}{|c|}{ 1. No intentadas. }} & 2. $>12 C$ & $200<8$ & \multicolumn{2}{|c|}{ 3. $109-120$ ó $80-89$} \\
\hline & & & & & & & nsertar & ar ritmo medio apr & $\begin{array}{l}\text { oreciado: } \\
\text { o. }\end{array}$ \\
\hline \multicolumn{10}{|c|}{ ETAPA 23: Compresión (profundidad en mm) } \\
\hline \multicolumn{6}{|c|}{$\begin{array}{l}\text { Profundidad de las compresiones } \\
\text { percibida por el evaluador (mirar la primera serie de } \\
\text { compresiones) }\end{array}$} & $\begin{array}{l}\text { 1. No } \\
\text { realizad }\end{array}$ & das 2 & $\begin{array}{l}\text { 2. Mayoría } \\
\text { Incorrectas }\end{array}$ & $\begin{array}{l}\text { 3. Mayoría } \\
\text { correctas }\end{array}$ \\
\hline
\end{tabular}




\section{4a parte: secuencia de DEA Shock 4}

(Después de 1 minuto de RCP, el DEA indica "examine al paciente........"

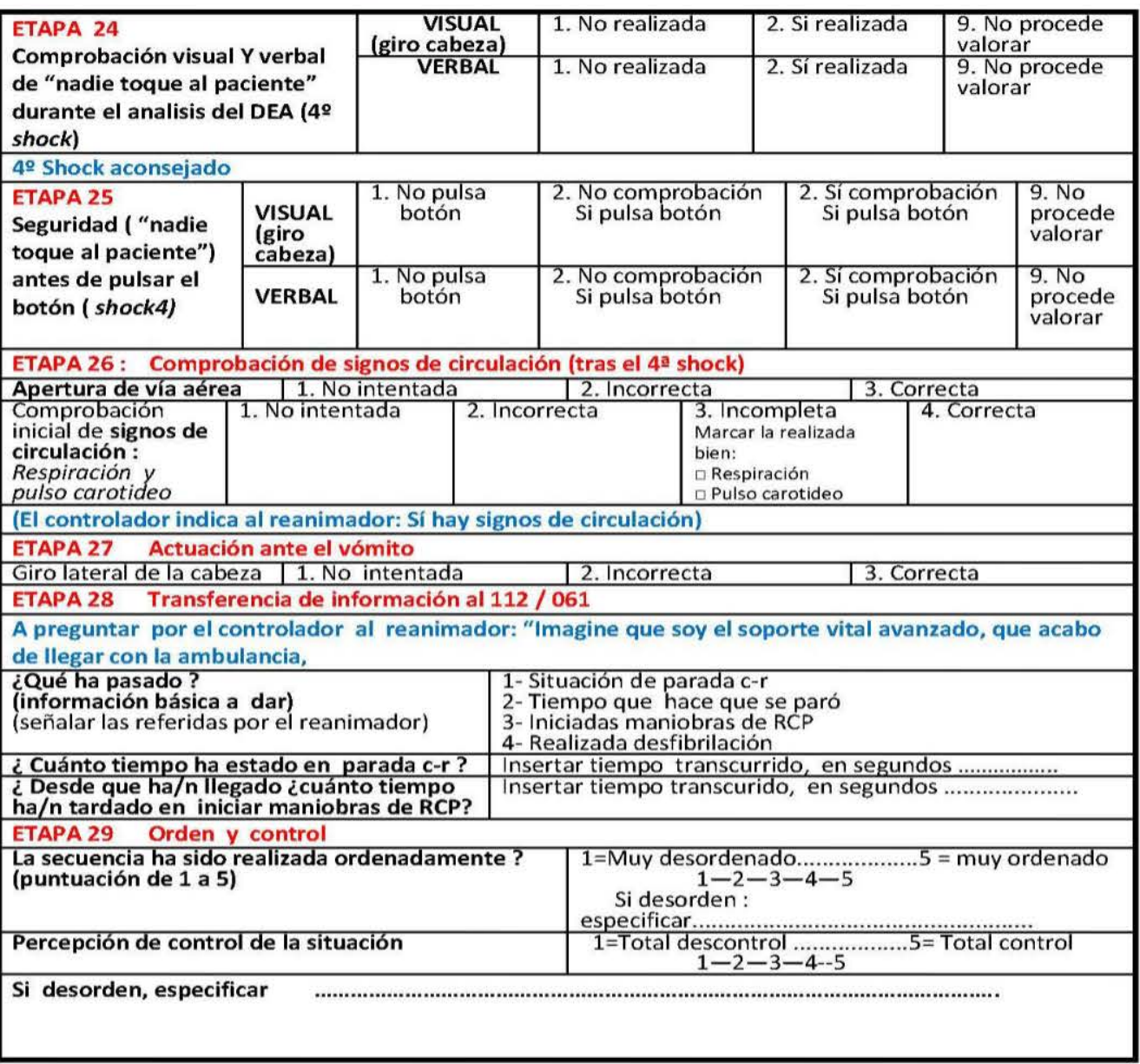




\section{Anexo 3. Encuesta de satisfacción de la actividad formativa}

Encuesta de satisfacción de la actividad formativa

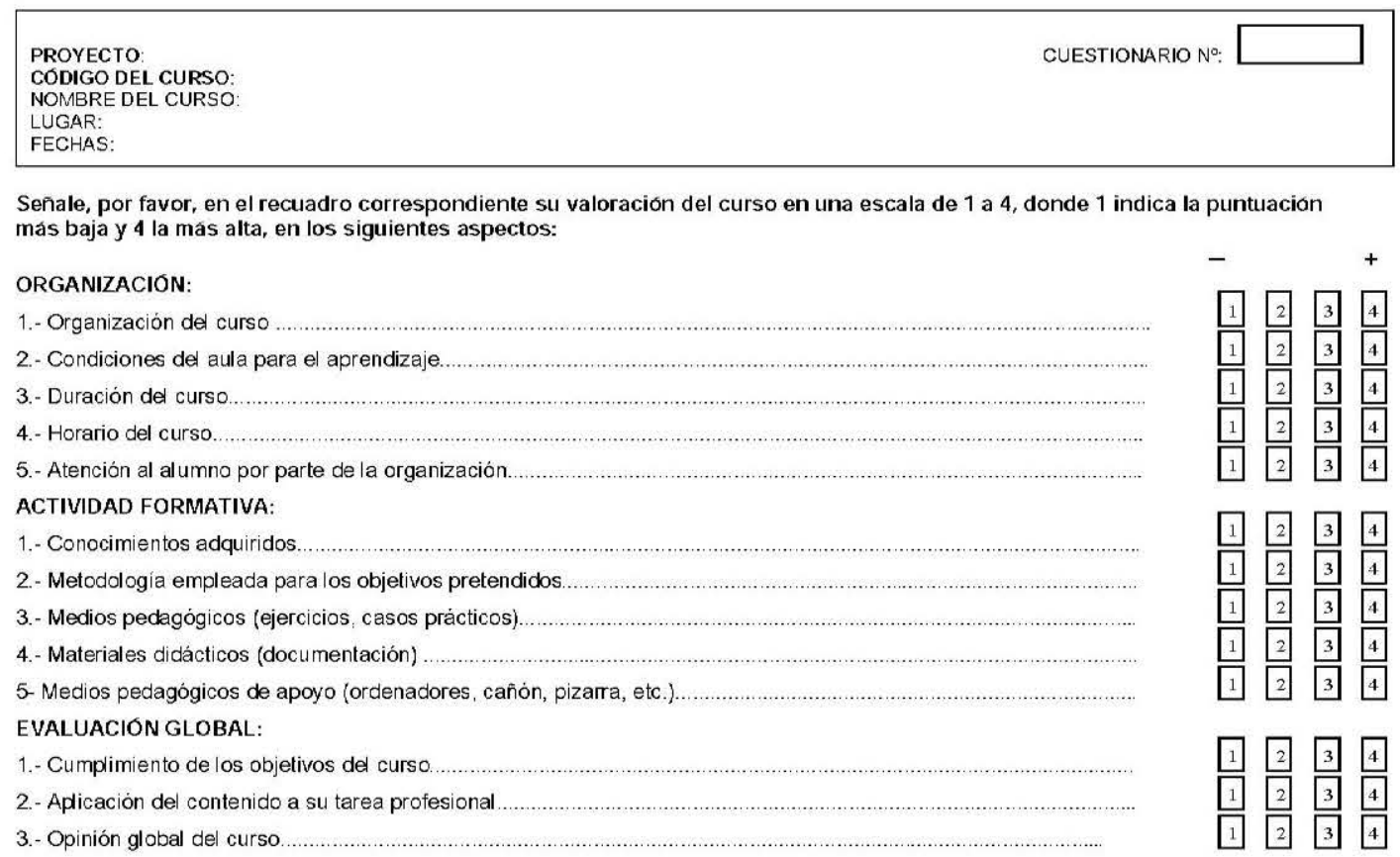

PROFESORADO:

1. Conacimientos en la materia impartida

2. Claridad de sus respuestas

3. Dominio en los aspectos prácticas

4. Interés que despierta en clase.

5. Cumplimiento del programa

6. Fomento de la participación de los alumnos.......

7. Evaluación global

\begin{tabular}{|c|c|c|}
\hline $\mathrm{D} / \mathrm{D}^{\mathrm{a}} \ldots \ldots \ldots$ & $\mathrm{D} / \mathrm{D}^{\mathrm{a}} \ldots$ & $\mathrm{D} / \mathrm{D}^{\mathrm{a}} \ldots \ldots \ldots$ \\
\hline 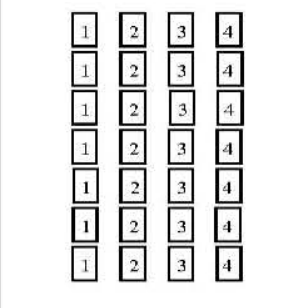 & 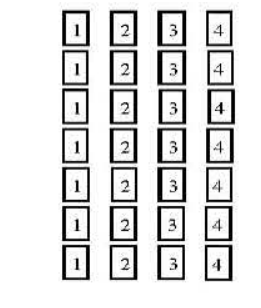 & 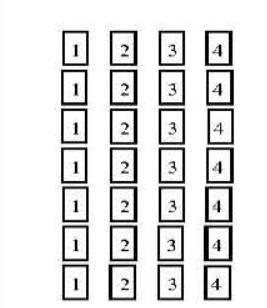 \\
\hline
\end{tabular}

